\title{
O CÁlCULO DIFERENCIAL E INTEGRAL E A MATEMÁTICA DO CURSO SECUNDÁRIO
}

\author{
DIFFERENTIAL AND INTEGRAL CALCULUS AND \\ HIGH SCHOOL MATHEMATICS
}

Eliene Barbosa Lima ${ }^{1, *}$

\begin{abstract}
RESUMO: Neste texto, investigamos historicamente os saberes presentes no curso de cálculo diferencial e integral do curso de matemática no Instituto de Matemática da Universidade Federal da Bahia, no período de 1968 a 1978. A pesquisa buscou responder ao seguinte questionamento: "Que relações foram estabelecidas entre o curso de cálculo diferencial e integral e a matemática do curso secundário?” Para tanto, fizemos uso de uma literatura vigente, de um modus operandi da história cultural e de fontes históricas. Assim, apropriando-nos do debate de uma história da educação sobre saberes profissionais da docência, consideramos que os saberes para o curso de cálculo diferencial e integral não foram pensados e organizados para a prática específica da docência em sala de aula.
\end{abstract}

Palavras-chave: Cálculo diferencial e integral. Saberes profissionais da docência. Universidade Federal da Bahia

\begin{abstract}
In this text, we investigated, historically, the knowledge present in the differential and integral calculus course of the mathematics course at the Universidade Federal da Bahia’s Instituto de Matemática, from 1968 to 1978. The research sought to answer the following question: 'What relationships were established between the differential and integral calculus course and the High School mathematics?' For that, we used the current literature, of a cultural history modus operandi and historical sources. Thus, appropriating the debate of a history of education about professional teaching knowledge, we consider that the knowledge for the differential and integral calculus course was not thought and organized for the specific practice of teaching in the classroom.
\end{abstract}

Keywords: Differential and integral calculus. Professional teaching knowledge. Universidade Federal da Bahia.

\footnotetext{
1.Universidade Estadual de Feira de Santana - Departamento de Ciências Exatas - Feira de Santana (BA), Brasil.

*Autora correspondente: eblima@uefs.br

Número temático organizado por Wagner Rodrigues Valente
} 


\section{Introdução}

Era 17 de agosto de 1968, quando um grupo de professores realizou a primeira reunião no salão nobre da Escola Politécnica da Universidade Federal da Bahia (UFBA) para dar continuidade ao processo de transformação do Instituto de Matemática (IM), não mais atrelado ao Instituto de Física (UFBA, 1968g). Até o ano letivo de 1968, o curso de matemática esteve sob a responsabilidade da Faculdade de Filosofia ${ }^{1}$ da UFBA, apesar de o IM ter sido fundado em agosto de 1960 como Instituto de Matemática e Física (IMF)².

Mediante o Decreto n. 62.241, de 8 de fevereiro de 1968, que reestruturou a UFBA, tal instituição passou a ser constituída por 24 unidades universitárias, entre elas o IM, compreendido como unidade de ensino e pesquisa básicos (BRASIL, 1966; 1968a). Tratava-se de um preâmbulo importante para uma inevitável reforma universitária em vias de ser promulgada, o que foi efetivado em 28 de novembro de 1968 , sob a lei n.5540, a qual fixou organização e funcionamento do ensino superior brasileiro, bem como a sua articulação com as escolas de nível básico (BRASIL, 1968b). Por meio dessa lei, criaram-se os institutos e departamentos, uma redistribuição não apenas espacial, mas também dos contingentes administrativo e docente (MARQUES, 2010, p.289).

A reunião em pauta, portanto, configurava ação importante acerca dos trâmites legais que precisariam ser executados para viabilizar o funcionamento do IM em conformidade com o que preconizavam o Decreto n. 62.241/1968 (BRASIL, 1968a) e o novo estatuto da UFBA (UFBA, 1968a), aprovado sob o parecer favorável de, entre outros, Newton Sucupira e Valnir Chagas, em 4 de julho de 1968 - portanto, antes da lei da reforma das universidades brasileiras entrar em vigor. Contudo, por causa disso, visando à sua total convergência com essa lei, tal estatuto sofreu algumas modificações. Uma delas referia-se à extinção das cátedras, ${ }^{3}$ cuja designação havia sido utilizada para categorizar os professores da UFBA. Sob essa conjuntura, formalizava-se uma nova regulamentação, um novo “[...] sistema de normas da profissão docente [...]" (NÓVOA,1999, p. 18, grifos do autor) para a carreira do professor no magistério superior, de modo geral, e, em particular, para o professor de matemática.

Iniciava-se, dessa forma, mais um capítulo da profissionalização docente de nível superior na Bahia, em especial da formação de professores licenciados no curso de matemática da UFBA, sob o domínio do IM.

De fato, assim como outras profissões, os exercícios docentes, em diferentes tempos históricos, foram construídos e reconstruídos por uma pluralidade de variáveis móveis, não desprezíveis e não hegemônicas, nos mais diversos contextos socioculturais, inclusive em regiões de um mesmo país, como o Brasil. Não se trata, portanto, de um fenômeno imóvel, mas em movimento, configurando, por esse prisma, processos de profissionalização docente, multifacetados por uma diversidade de instâncias e instituições voltadas para formar o professor em diferentes níveis de escolarização (GARNICA, 2013). Contudo, autores devotados aos estudos da constituição das profissões em um sentido mais amplo, como a socióloga Larson (2013), afirmam que há certos consensos em torno de dimensões mais gerais dos processos de profissionalização, as quais são compartilhadas por uma comunidade corporativa de especialistas, mas sem significar uma hierarquização de etapas. Segundo Larson:

[a] dimensão cognitiva é centrada sobre o corpo de conhecimento e técnicas que os profissionais aplicam em seu trabalho e sobre o treinamento necessário para dominar tais conhecimentos e habilidades; a dimensão normativa cobre a orientação de serviços de profissionais e sua ética diferenciada, que justifica o privilégio da autorregulação 
concedido a eles pela sociedade; a dimensão avaliativa implicitamente compara profissões com outras ocupações, ressaltando as características singulares das profissões de autonomia e de prestígio (2013, p. XI; tradução nossa).

Tais dimensões, de modo geral, também foram evocadas por Nóvoa (1999) e Tardif (2013) em suas respectivas análises essencialmente voltadas para os processos de profissionalização docente. Todavia, sob o universo dessas dimensões, que elementos poderiam garantir o exercício da docência, em particular, e em geral, que elementos poderiam dar um caráter distintivo às profissões? O que parece um elemento importante nesse sentido diz respeito à constituição progressiva de saberes próprios para o exercício profissional. Assim, entre outros elementos de dimensões gerais de Larson (2013), sinalizados anteriormente, escolhemos investigar historicamente os saberes presentes no curso de cálculo diferencial e integral do curso de matemática no IM da UFBA, entre 1968 a 1978. Fizemos esse recorte temporal, tendo, como início, o ano em que o curso de matemática (em particular as disciplinas de conteúdos matemáticos, como cálculo diferencial e integral) passou a ser responsabilidade do IM e, como término, o último ano em que prevaleceu o programa de cálculo diferencial e integral, constituído em decorrência de uma reformulação curricular do curso de matemática após a reforma universitária de 19684. Essa investigação foi norteada pelo seguinte questionamento: "Que relações foram estabelecidas entre o curso de cálculo diferencial e integral e a matemática do curso secundário?”

\section{Docência, profissão, saberes}

Neste texto, tratamos, em particular, dos saberes ditos objetivados, no sentido atribuído por Barbier (2014), constituído em um dado tempo histórico na formação do professor, os quais são construídos historicamente e traduzem-se em enunciados coerentes, despersonalizados, teorizados e passíveis de serem apropriados e compreendidos fora do contexto em que ocorreram. Tais saberes foram legitimados por uma comunidade científica e/ou profissional. Na própria síntese dessa autora, os saberes objetivados:

[...] podem ser definidos como enunciados proposicionais, sujeitos a objetos de julgamento social que vão lhes dar registro de verdade ou eficácia. Podem mesmo ser considerados duplamente como a seguir: de uma parte, formalizam uma representação do real (dizem algo sobre a realidade); de outra, enunciam uma correspondência, um link entre essa representação e o objeto representado (a noção de verdade e a afirmação dessa correspondência). (BARBIER, 2014, p.9; tradução nossa).

Não correspondem, portanto, aos saberes da ação, considerados conhecimentos, na medida em que estão ligados à prática, à subjetividade, à informalidade e às experiências e competências adquiridas pelo sujeito em situação do exercício da docência. (BARBIER, 2014).

É sob a ênfase dos saberes objetivados que a Equipe de Pesquisa em História das Ciências da Educação (Erhise) da Universidade de Genebra vem ampliando o debate sobre profissionalização docente. Em seus estudos, são colocados em primeiro plano os processos e dinâmicas da constituição de saberes profissionais da docência, por meio de uma investigação histórico-social. Nesses termos, foram caracterizados dois tipos de saberes objetivados, vinculados às instituições formais, quais sejam: saberes a ensinar e saberes para ensinar - de naturezas diferentes, porém, articulados. 
Em síntese, os saberes a ensinar podem ser definidos, a priori, como objetos de ensino “[...] emanados dos campos disciplinares de referência produzidos pelas disciplinas universitárias (saberes disciplinares ou saberes concernentes aos saberes a ensinar).” (BORER, 2017, p. 175, grifos do autor). Contudo, não apenas sob essa dimensão. Para além de uma mera listagem de conteúdos, os saberes a ensinar podem ser configurados como "[...] o resultado dos processos complexos que transformam fundamentalmente os saberes a fim de torná-los ensináveis. Esse processo pode até conduzir à criação de saberes próprios às instituições educativas, necessárias a elas para assumirem as suas funções." (HOSFSTETTER; SCHNEUWLY, 2017, p. 133).

De outra parte, os saberes para ensinar podem ser traduzidos como ferramentas de trabalho no âmbito do ensino e da formação do professor, as quais envolvem didáticas e/ou metodologias de ensino atreladas às diferentes disciplinas escolares e, ainda, os estudos pedagógicos, "[...] principalmente os ensinos de pedagogia teórica e prática, de psicologia, de ciências da educação [...]” (BORER, 2017, p. 180). Todavia, os saberes para ensinar tratam também:

[...] de saberes sobre "o objeto" do trabalho de ensino e de formação (sobre os saberes $a$ ensinar e sobre o aluno, $\mathrm{o}$ adulto, seus conhecimentos, seu desenvolvimento, as maneiras de aprender etc.), sobre as práticas de ensino (métodos, procedimentos, dispositivos, escolha dos saberes $a$ ensinar, modalidades de organização e de gestão) e sobre a instituição que define o seu campo de atividade profissional (planos de estudos, instruções, finalidades, estruturas administrativas e políticas etc.). (HOFSTETTER; SCHNEUWLY, 2017, p. 134, grifos dos autores).

Em particular, para Valente, as pesquisas da Erhise, estão possibilitando interpretar que, ao longo do tempo, houve processos de objetivação, os quais “[...] resultam na constituição dos saberes objetivados." (2019, p.17). Sob esse ponto de vista, ponderou que " $[\mathrm{t}] \mathrm{er}$ em conta processos de objetivação leva-nos a considerar saberes 'ainda não objetivados', por exemplo, saberes da ação." (VALENTE, 2019, p.17, grifos do autor). Nessa perspectiva, Valente considerou que é plausível colocar "[...] em relação os saberes instituídos, objetivados face àqueles saberes da ação." (2019, p.18). Dessa forma, tendo esse olhar em relação às pesquisas da Erhise, Valente (2019) fez uma apropriação ${ }^{5}$ (CHARTIER, 1988) dos saberes objetivados em termos de uma matemática a ensinar e uma matemática para ensinar, por tomar a matemática e o seu ensino como objetos de pesquisa. Nesse sentido, argumentou que,

[e]ssas novas bases teórico-metodológicas mobilizadas para tornar inteligíveis processos e dinâmicas de produção dos saberes profissionais dos professores e, em especial, saberes profissionais do professor que ensina matemática coloca [sic] no centro das discussões o saber, traz [sic] para o debate a epistemologia, tratada no campo pedagógico, problematiza [sic] os saberes pedagógicos em termos de processos de objetivação, dá [sic] sentido às investigações que visam compreender como se constituem os saberes objetivados em sua articulação com os saberes da ação. (VALENTE, 2019, p.19).

Portanto, para Valente, “[...] instala-se um novo campo de investigações que remete ao estudo [...] das dinâmicas de articulação entre a matemática a ensinar e a matemática para ensina." (2019, p.19).

Sob essa ótica, em cada tempo histórico, foram sedimentados saberes profissionais como necessários e suficientes para o ofício específico da docência, em particular, dos professores que ensinariam matemática nas escolas secundárias. Um exemplo, nesse sentido, foram os saberes para 
o curso de cálculo diferencial e integral, do curso de matemática sob a responsabilidade do IM da UFBA a partir do ano letivo de 1968.

\section{Por uma Constituição de Saberes Profissionais para a Formação do Professor de Matemática}

Na Bahia, até 1941, quando foi fundada a Faculdade de Filosofia da Bahia (FF) - espaço específico de formação de professores para a docência em nível secundário, com cursos autônomos para esse exercício -, o ensino de matemática geralmente era uma das atribuições dos engenheiros, formados na Escola Politécnica da capital baiana, Salvador, o que se dava desde 1896, quando foi criada essa instituição. (FF, 1941; 1942; DIAS, 2002; LANDO, 2012).

Esse grupo corporativo dominava o exercício dos magistérios superior e secundário da matemática em diversos contextos brasileiros, mediante reconhecimento político e legitimação social, visto que não havia uma jurisdição própria voltada para uma educação formal técnica e autônoma, regulamentada oficialmente. Desse modo, as escolas de engenharias simbolizavam o caminho natural daqueles que manifestavam desejo pelos estudos matemáticos. (DIAS, 2002; LIMA, 2016).

Esse ponto de inflexão foi estabelecido a partir da criação de um estatuto próprio para a formação do professor secundário em nível superior, como bem enfatizou Francisco Luís da Silva Campos (1891-1968) quando assumiu o Ministério da Educação e Saúde Pública em 1930, instaurado no governo provisório (1930-1934) de Getúlio Dorneles Vargas (1882-1954). Em seu discurso, Campos proferiu as seguintes palavras: "queremos ter professores sem cuidar de formá-los" (apud CASTRO, 1974, p. 629). Assim, ao expor as motivações sobre a promulgação de sua reforma do ensino secundário, pelo Decreto n. 19890, de 18 de abril de 1931 (BRASIL, 1931a), popularmente conhecido como Reforma Francisco Campos, sentenciou:

O Brasil não cuidou ainda de formar o professorado secundário, deixando a educação da sua juventude entregue ao acaso da improvisação e da virtuosidade, sendo inacreditavel [sic] que nenhum esforço haja sido tentado naquela direção. (CAMPOS apud CASTRO, 1974, p. 629).

Nesse sentido, Francisco Campos instituiu um pouco antes, por meio do Decreto n. 19851, de 11 de abril de 1931, sobre o estatuto das universidades brasileiras, a criação de faculdades de educação, ciências e letras, o que foi reiterado pelo Decreto n. 24279, de 22 de maio de 1934. Tais faculdades se transformariam em um locus a serviço do Estado (BRASIL, 1931b, 1934; CASTRO, 1974), dado que o mesmo discurso acerca da educação manifestado desde os tempos do Império permanecia. A educação era, ainda, considerada fator imprescindível para a construção de uma nação, com uma cultura própria, capaz de dar continuidade ao progresso e à modernização de uma emergente sociedade brasileira, rumo a crescentes urbanização e industrialização e alinhada às transformações que vinham ocorrendo mundialmente.

Dessa forma, a essas faculdades caberia ministrar "[...] o ensino superior de diversas disciplinas [...]” (BRASIL, 1931c, [s.p.]), tendo como objetivos:

[...] ampliar a cultura no domínio das ciências puras; [...] promover e facilitar a prática de investigações originais; [...] desenvolver e especializar conhecimentos necessários ao 
exercício do magistério; [...] sistematizar e aperfeiçoar, enfim, a educação técnica e científica para o desempenho profícuo de diversas atividades nacionais. (BRASIL, 1931c, [s.p.]).

Na prática, de acordo com Castro (1974) e sem explicitar as motivações, tais faculdades foram estabelecidas sob a nomenclatura de faculdades de "filosofia" ou de "filosofia, ciências e letras". A primeira, efetivamente implementada seguindo aproximadamente essa estruturação foi a Faculdade de Filosofia, Ciências e Letras (FFCL), criada junto à Universidade de São Paulo (USP), em 1934. Uma de suas formações era o curso das ciências matemáticas. Instaurava-se, dessa forma, um novo modelo de formação para o professor de matemática que ministraria aulas nas escolas secundárias brasileiras. Isso estava, porém, longe de ser o único e hegemônico mecanismo de aparelhar esse professor para o exercício docente institucionalizado por diversos governos brasileiros. Em particular, não houve uniformização, inclusive em instituições congêneres, como no curso de matemática ofertado, respectivamente, na FF e na FFCL, pelo menos no período de 1943 a 1968.

Por exemplo, no curso de matemática da FFCL, o ensino de análise matemática, desde o período de sua criação, em 1934, seguiu os preceitos de uma matemática dita moderna que começou a ser constituída a partir do século XIX e consolidada no século XX. Nesse contexto, a análise matemática, que envolvia os cálculos diferencial e integral, foi abordada a partir de uma concepção discreta numérica, centrada na noção de limite, impulsionada por Augustin Louis Cauchy (1789-1857), Karl Weierstrass (1815-1897) e Richard Dedekind (1831-1916). Já na FF, o ensino de análise matemática, na nossa interpretação, foi conduzido sob a ótica de uma matemática clássica, vinculada, principalmente, aos trabalhos de Gottfried Wilhelm von Leibniz (1646-1716) e Isaac Newton (1642-1727), baseados em uma noção infinitesimal. (LIMA; DIAS, 2010a; LIMA, 2012). Isso prevaleceu, apesar da vigência do Decreto n. 1.190, de 4 de abril de 1939, que organizou a Faculdade Nacional de Filosofia (FNFI) da Universidade do Brasil, no Rio de Janeiro, como modelo oficial de todos os estabelecimentos de ensino que eram congêneres a essa Faculdade, a partir do ano escolar de 1940 (BRASIL, 1939). Na FNFI, o programa da disciplina de Análise Matemática foi elaborado sob uma apropriação da matemática moderna.

Contudo, concentrando-nos apenas nesses espaços de formação do professor em nível superior, é inegável a constituição de critérios específicos para o exercício autônomo e integral da docência nas escolas de nível secundário, ou seja, da profissionalização desses professores.

Um desses critérios, para o estabelecimento do monopólio desses espaços na formação docente consistiu na construção de saberes profissionais próprios, que deveriam ser dominados para o exercício da docência nesse nível de ensino. Tais saberes, dessa forma, configuravam, na nossa ótica, elemento importante de legitimação e diferenciação de um professor secundarista, em especial de matemática, das outras profissões. Esses saberes não foram estáticos, mas se constituíram e modificaram ao longo do tempo, a depender de fatores que envolviam, entre outros aspectos, mudanças de concepções do que se entendia por professor e transformações no contexto sociocultural e no sistema educacional vigentes em um determinado período.

\section{Os Saberes para o Curso de Cálculo Diferencial e Integral do Curso de Matemática na Era do Instituto de Matemática}

O IM, no ano letivo de 1968, assumiu não apenas as disciplinas específicas ${ }^{6}$ dos saberes matemáticos da graduação em matemática - bacharelado e licenciatura -, que estavam a cargo da FF, mas também aquelas que eram ministradas nos cursos de física, arquitetura, farmácia e química. 
Em específico, nesse ano, o IMF ofertou as seguintes disciplinas para a graduação em matemática: Equações Diferenciais; Cálculo Numérico; Álgebra Linear; Funções Analíticas; Geometria Analítica; Geometria Diferencial; Geometria Descritiva; Desenho Geométrico; Cálculo Vetorial e Álgebra; Cálculo das Variações; Funções Especiais; Cálculo Diferencial e Integral I; Cálculo Diferencial e Integral II; Álgebra Moderna; e Fundamentos de Matemática Elementar (UFBA, 1968b). Essas disciplinas, com exceção de Fundamentos de Matemática ${ }^{7}$ Elementar, pareceram-nos compreender os ciclos comuns básico e profissional dos $\operatorname{cursos}^{8}$ de bacharelado e licenciatura em matemática. Nelas, era ministrado um saber a ensinar, tendo como objetivo, para o ciclo básico, “[...] familiarizar o aluno com os métodos universitários de estudo e pesquisa, aprimorar-lhe a formação humanística e possibilitar maior rendimento no ciclo posterior [...]" (UFBA, 1968a, p. 23). Já, para o ciclo profissional, intencionava-se "[...] proporcionar ao aluno os conhecimentos que o habilitem ao exercício da pesquisa e ao desempenho profissional." (UFBA, 1968a, p. 23).

Nesse novo contexto, a disciplina de Cálculo Diferencial e Integral I foi paulatinamente reorganizada no âmbito do curso de matemática na era do IM, em especial, para atender às novas exigências de legislações que estavam sendo prioritariamente estabelecidas pelo Conselho Federal de Educação $(\mathrm{CFE})^{9}$ em um movimento que antecedia a própria promulgação da reforma universitária, ocorrida em 28 de novembro de 1968. Um desses indicativos dizia respeito à constituição de novos currículos dos cursos de graduação (BRASIL, 1968c).

Esse processo de transformações para o ensino de cálculo diferencial e integral foi regularizado em um novo programa no ano de 1972. Por exemplo, sob a nomenclatura de Cálculo I, foram estabelecidos os seguintes conteúdos (matemática a ensinar): 1) inequações a mais de uma variável. Noções de programação linear; 2) Funções de uma variável real. Tabelas e gráficos. Domínio e imagens. Funções elementares: algébrica, circulares, exponenciais e hiperbólicas; 3 ) Limite: definição, propriedade. Teoremas gerais. Limites fundamentais: infinitésimos; 4) Continuidade: definição, propriedades. Teoremas gerais; 5) Taxa de variação. Derivadas: regras de derivação. Derivadas das funções elementares, derivadas de funções compostas e implícitas. Curvas em equações paramétricas: derivadas; 6) Diferencial: propriedades fundamentais, derivadas e diferenciais sucessivas. Cálculo de erros; 7) Teoremas de Rolle, Lagrange, Cauchy e L'Hôpital; 8) Fórmulas de Taylor e de MaclaurIn: algumas funções elementares: $e^{x}, \ln (1+x),(1+x)^{0}$, sen $x, \cos x$, sh $x$, ch $x$ etc; 9) Teoria geral dos máximos e mínimos: concavidade, pontos de inflexão, construção de gráficos, assíntotas; e 10) Contato de curvas planas: círculo osculador, comprimento de arco, diferencial do arco, curvatura.

Em alguns desses conteúdos, foi possível relacionar outros pontos apresentados que, na nossa concepção, poderiam corresponder a saberes "sobre 'o objeto' do trabalho de ensino e de formação", ou seja, que tratavam de uma matemática para ensinar, mas dimensionados no próprio campo de conhecimento da matemática. Em outros termos, por parecerem ter sido utilizados como dispositivos para melhor entender as suas respectivas teorias. Referimo-nos aos seguintes pontos: aplicações das teorias de limite, derivadas, dos teoremas de Rolle, Lagrange, Cauchy e L'Hôpital e, ainda, da teoria geral dos máximos e mínimos, incluindo uma interpretação geométrica de derivadas e diferencial. (UFBA, 1972).

No ano letivo de $1973^{10}$, foram excluídos do programa de 1972 os dois primeiros tópicos que aparentemente correspondiam a conteúdos vigentes nas escolas secundárias. Nenhuma outra modificação foi feita até o ano de 1978, quando houve uma efetiva estruturação dos conteúdos que deveriam ser ministrados no curso de cálculo diferencial e integral I, materializada sob uma nova nomenclatura - Cálculo I-A -, a partir do ano letivo de 1979. Dessa forma, encerrou-se o ciclo da 
reformulação curricular do curso de matemática ocorrido logo após a reforma universitária de 1968. (UFBA, 1972; 1973-1978; 1979-1985).

Nessa nova ordem, pelo menos a disciplina Cálculo Diferencial e Integral I, quando foi ministrada por Omar Catunda ${ }^{11}$, seguiu os ritos equiparáveis aos que eram postos, ao menos formalmente, para a cadeira de Análise Matemática do curso de matemática da FF, a qual englobava o ensino dos cálculos diferencial e integral. Isso prevaleceu independentemente de a disciplina ser ministrada para o bacharelado ou para a licenciatura ou, ainda, para as demais graduações que tinham o ensino de cálculo diferencial e integral em sua grade curricular. Essa dinâmica pareceu estar relacionada ao fato de que essa disciplina ter sido estabelecida como um dos cursos básicos ofertados pelo Departamento de Matemática Geral ${ }^{12}$ do IM.

Por esse prisma, no ano letivo de 1968, por exemplo, Omar Catunda ministrou a disciplina Cálculo Diferencial e Integral I para alunos das primeiras séries dos cursos de matemática e física. Nessas aulas, contou com o auxílio da pós-graduanda Célia Maria Ganem Pitangueira, que era responsável pelas aulas de exercícios (UFBA, 1968b; 1968d).

Já no ano de 1970, Catunda teve como seu assistente Fernando Sá ${ }^{13}$, que tinha concluído o curso no ano anterior. Não era por acaso que Catunda ensinava uma disciplina que integrava os curso básicos da graduação, visto que ele já era um experiente e reconhecido matemático-professor. De acordo com Fernando Sá, Catunda fazia questão de ministrar essas disciplinas, pois na sua concepção,

[...] os cursos iniciais da graduação teriam que ser ensinados por professores mais experientes. Para ele, isso evitaria a deformação dos alunos. Assim, apesar de as turmas serem numerosas, o Prof. Catunda fazia questão de ensinar o curso de Cálculo. Nesses cursos, Catunda abordava as estruturas algébricas, números reais - a idéia [sic] do corte de Dedekind e se estendia até ao estudo da curvatura, evolutas, evolvente de curvas, ainda no primeiro semestre. (SÁ, 2005, [s.p.]).

Essa defesa de Catunda acerca dos professores que deveriam ensinar nos cursos iniciais destoou da cultura que foi vivenciada em outros cursos congêneres, como o de matemática da USP, logo após a reforma universitária de 1968. De acordo com Gabriel Lima (2012), as disciplinas iniciais desse último curso ficavam, geralmente, a cargo de professores recém-formados, contratados em função de essa reforma ter prescrito que todas as disciplinas de matemática deveriam ser ofertadas em um único instituto.

Já em relação aos conteúdos mencionados por Fernando Sá, pelo menos até o ano de 1970, Catunda pareceu ter continuado a seguir o programa e a abordagem de ensino que ele, ao longo dos anos, trabalhou na FFCL da USP, como catedrático de sua antiga cadeira de Análise Matemática. Nessa Faculdade, no programa aprovado pela congregação para o ano letivo de 1953, constava, entre outros conteúdos, os seguintes: pontos singulares das curvas planas; assíntotas; envoltórias; curvatura; evolutas e evolventes; curvas reversas; triedro fundamental; curvatura e torsão; classificação dos pontos regulares de uma superfície; e curvatura das curvas situadas em uma superfície. (FFCL, 1953). Tais conteúdos já eram tradicionalmente abordados na cadeira de Análise Matemática da FFCL desde o seu primeiro programa estabelecido em 1934 por Luigi Fantappiè (1901-1956) ${ }^{14}$ (FFCL, 1937).

Para além disso, Fernando Sá afirmou, ainda, que o curso de cálculo, ministrado por Omar Catunda na graduação, fazendo uso prioritariamente do livro de cálculo de Piskunov, tinha uma "[...] fundamentação teórica muito bem feita, que se avizinhava a um curso de análise [...]", no qual 
demonstrava "[...] tudo com muito rigor em um nível elevado [...]" (SÁ, 2005, [s.p.]), perspectiva que também se fez presente na USP após a reforma universitária de $1968,{ }^{15}$ mostrando, dessa forma, a permanência do alinhamento de Catunda com a cultura acadêmica dessa universidade.

No entanto, Catunda, para sua abordagem teórica rigorosa, sempre que possível, recorria antes à "intuição ${ }^{16}$ geométrica" (LIMA; DIAS, 2010). Talvez tenha sido por esses elementos que Catunda fez uso do livro de cálculo diferencial e integral de Piskunov, que, segundo Gabriel Lima (2012), também foi uma obra muito popularizada no curso de matemática da USP a partir da segunda metade da década de 1960. De acordo com esse autor, tal livro tinha como característica marcante "[...] a quase que total inexistência de exploração das noções intuitivas dos conceitos, que já são apresentados, na maioria das vezes, de maneira formal." (LIMA, 2012, p. 283). Apesar disso, trazia, ainda conforme análise de Gabriel Lima (2012), algumas interpretações geométricas para auxiliar na definição de determinados conteúdos matemáticos, como a integral indefinida, que, na ótica desse pesquisador, “[...] nem sempre presente nos textos de Cálculo." (LIMA, 2012, p. 283).

Assim, a partir dessa análise, interpretamos que, para Catunda, estava em primeiro plano a pesquisa matemática, pois ele acreditava que, por via dela, poder-se-ia intervir eficazmente no ensino de matemática nas escolas secundárias. Transparecia, dessa forma, que, para ele, era indiferente a formação do bacharel e do licenciado em matemática. Por isso, na nossa concepção, Catunda ratificava o seu alinhamento com as ideias de Luigi Fantappiè, seu mentor na USP, sobre a irrelevância dos cursos de didáticas para a formação do professor de matemática. Nesse sentido, Catunda costumava afirmar:

Eu sempre julguei, e tenho certeza de que esse julgamento é universal, que um bom professor tem que ser um permanente estudioso da matéria que leciona, a fim de aprimorar e atualizar, de ano para ano, o seu ensinamento, o que acarreta maior confiança e estima dos seu [sic] alunos. Mas parece que pelas idéias [sic] dominantes, é melhor que ele esqueça muito do que aprendeu a fim de atingir o mesmo nível mental dos alunos e tornar-se, assim, "um bom didata" (CATUNDA, 1973, [s.p.]).

Tal linha de raciocínio não difere muito daquela exposta por Benedito Castrucci (1909-1995), aluno da secção das ciências matemáticas da FFCL de 1937 a 1939. Ele relembrou que não fez o curso de didática para concluir o curso de matemática, porque recebeu a seguinte orientação de Fantappiè:

[...] estuda Matemática, deixa de lado essas coisas de Didática, porque Didática só tem uma regra boa: saber a matéria, se você souber a matéria, o resto você é um artista e se for um mau artista será a vida toda, se for um bom artista será um bom professor. O resto põe tudo de lado." (CASTRUCCI apud FREITAS, 1992, p. 50).

Prevalecia, à vista disso, baseando-nos nos estudos de Nóvoa (1999), o entendimento de que ser professor de matemática continuava sendo uma questão de vocação, sacerdócio, herança de uma ideologia dos tempos dos jesuítas. Em suma, ser professor era, ainda, no entendimento de Catunda, uma questão de bossa.

Entretanto, pelas fontes constituídas para a produção desse artigo, não é possível ponderar que esse olhar de Catunda sobre a formação no curso de matemática do IM reverberou após o ano de 1970 e, ainda, se o próprio Catunda continuou lecionando cálculo diferencial e integral para os ingressantes até 1976, quando completou 70 anos e obteve sua aposentadoria compulsória. Há, apenas, indicativos que essa cultura tenha sido apropriada pelas demais professoras ${ }^{17}$ que seguiram no corpo docente do reestruturado IM. Isto porque, essas professoras continuaram sua formação profissional, após concluírem o curso de matemática, sob a liderança do próprio Catunda no então IMF, ainda na década de 1960. 


\section{Considerações Finais}

Neste artigo, investigamos historicamente os saberes presentes no curso de cálculo diferencial e integral do curso de matemática no IM da UFBA, entre 1968 a 1978. Assim, construímos uma síntese, visando responder à seguinte inquietação: “Que relações foram estabelecidas entre o curso de cálculo diferencial e integral e a matemática do curso secundário?”

Nesse contexto, sob a tutela do IM desde o ano letivo de 1968, as disciplinas do curso de matemática, comuns para o bacharelado e a licenciatura e que compunham a maior parte de sua grade curricular, primavam, pelo domínio de saberes devedores do próprio campo acadêmico da matemática, no sentido atribuído por Hofstetter e Schneuwly (2017).

Nesses termos, a licenciatura em matemática da UFBA, no período analisado, que se traduzia como um espaço de formação para a docência em matemática, primava, no nosso entendimento, por uma matemática a ensinar sob uma concepção implícita de que quem saberia a matemática superior dominaria a matemática elementar presente nas escolas. Sob essa ótica, a matemática para ensinar era uma ferramenta de trabalho para viabilizar a matemática do campo disciplinar do matemático, sem uma devida importância para os saberes das ciências da educação, enfim, para questões ligadas à aspectos didático-pedagógicos. Tal percepção evidenciava, na nossa leitura, uma defesa de que o saber avançado englobaria o saber elementar. A escola, nesse caso, era compreendida como um ambiente de reprodução do campo disciplinar, na medida em que os saberes elementares deveriam ser ensinados como primeiros degraus dos saberes avançados. Sem entrar no mérito das questões didático-pedagógicas, essa posição que pareceu ocupar a matemática elementar em relação ao ensino superior na licenciatura em matemática do IM, começou a ser repercutida em uma comunidade de matemática, tendo como um de seus principais vetores Felix Christian Klein (1849-1925).

De fato, Klein, em 1908, já mostrava preocupações, em suas aulas para o professor secundário, acerca do crescente distanciamento entre os progressos da matemática e da matemática em nível secundário ${ }^{18}$. Nesse sentido, Felix Klein propôs o ensino de matemática elementar sob o ponto de vista superior, tendo como pano de fundo a seguinte argumentação: "É notável que os desenvolvimentos modernos passaram pelas escolas sem causar mínimo efeito na instrução. A razão é que a instrução matemática e os progressos constantes da pesquisa matemática perderam todo contato entre si após o início do século XIX” (apud BALDIN, 2011, p. 2).

Essas ideias de Klein foram recentemente retomadas em nível internacional, inclusive no Brasil, no âmbito do Projeto Klein for the 21st century. No contexto brasileiro, esse projeto é coordenado pela Sociedade Brasileira de Matemática (SBM), tendo como parcerias a Sociedade Brasileira de Educação Matemática e a Sociedade Brasileira de Matemática Aplicada e Computacional, bem como a Sociedade Brasileira de História da Matemática (para mais informações, ver: SBM, [s.d]; BALDIN, 2011; COMITÊ EDITORIAL, 2017). Tal projeto coloca em primeiro plano a articulação da matemática elementar do ensino com a matemática de formação do professor, constituindo, portanto, um modo de estabelecer uma "ponte" do campo disciplinar com o campo da docência. Contudo, mesmo reconhecendo a necessidade de uma análise mais aprofundada, a qual foge ao objetivo deste texto, é possível ponderamos que essa articulação parece continuar não levando em consideração a cultura escolar como um lugar de produção de saber e/ou que a matemática elementar não equivale a um degrau inferior da matemática superior.

O que parece central argumentarmos neste momento é que a defesa da matemática elementar sob o ponto de vista superior conduziu o ensino do cálculo diferencial e integral, visto na formação 
de professores de matemática da UFBA - o qual deveria ser de uma matemática de formação, isto é, de uma matemática para ensinar - de forma desarticulada com uma matemática a ensinar que estava na escola secundária.

Essa lógica, inclusive, era estendida aos cursos de outras graduações que tinham disciplinas de cunho matemático ofertadas pelo IM. À vista disso, tratava-se de uma prática que prevalecia independentemente da carreira profissional almejada, ou seja, permanecia o já conhecido " $3+1$ " 19 para universo das licenciaturas.

Assim, o curso de matemática, na era do IM, foi conduzido sob o ponto de vista do bacharelado de matemática, como modalidade de formação que prevalecia também na licenciatura em paralelo à legislação brasileira em vigor no período englobado em nossa pesquisa. Foi essa a identidade matemática seguida, por exemplo por Omar Catunda no exercício de sua docência vinculada ao IM, que começou a ser constituída ainda no âmbito da cadeira de Análise Matemática da FFCL da USP a partir de 1934, quando iniciou a sua docência como assistente de Luigi Fantappiè.

Dessa forma, a locação da disciplina Cálculo I como curso básico comum a todos os cursos que tinham essa disciplina - não sendo, portanto, conduzida para um saber específico da docência em matemática - conduziu-nos a caracterizá-la como saberes de uma cultura geral. Nesse sentido, fazia parte, conforme Larson (2013), de dimensões mais gerais dos processos de profissionalização, não específicos da jurisdição do professor que ensinaria matemática nas escolas secundárias.

Em suma, os saberes para o curso de Cálculo I não foram pensados e organizados tendo o aluno da licenciatura e a sua aprendizagem em primeiro plano; muito menos foram constituídos para a prática específica da docência em sala de aula. Seu foco estava no desenvolvimento da carreira do matemático, que comumente era visto como sinônimo de professor de matemática, mesmo tendo legislações distintas e objetivos diferentes.

Antes, no período do curso de matemática na FF, a disciplina de análise matemática, que englobava o ensino dos cálculos diferencial e integral, ministrada pelo catedrático Luiz de Moura Bastos (1903-1988), ${ }^{20}$ foi direcionada para formar o professor de matemática com saberes profissionais que eram objetivados para o ensino de matemática nas escolas secundárias baianas. Portanto, de 1943 a 1968, o curso de Moura Bastos pareceu-nos ter seguido uma ordem inversa ao que foi defendido por Felix Klein, ainda que parecendo manter certa hierarquia. Nessa ordem, a cultura escolar do ensino secundário prevaleceu sobre a do ensino superior, ou seja, a matemática superior foi ministrada sob o ponto de vista do ensino elementar. (LIMA, 2019; LIMA; VALENTE, 2019).

Contudo, com a transferência do curso de matemática para o IM, predominou a busca pela secularização de um ensino de saberes sob o ponto de vista da produção do conhecimento matemático, não da organicidade desses saberes, seguindo a lógica da aprendizagem do aluno. Sob essa ótica, ser professor de matemática pareceu continuar sendo uma questão de bossa. Trata-se de uma herança que pode ser notada ainda nos dias de hoje, quando a identidade do professor de matemática é confundida com a do matemático e/ou quando há discursos de que, para o curso de licenciatura em matemática, são suficientes as disciplinas específicas da matemática, transformando todas as disciplinas pedagógicas em pseudociência. Essa concepção parece ser um elemento importante no distanciamento de uma articulação da matemática a ensinar e da matemática para ensinar, tendo como produto uma matemática do ensino, que vai se caracterizando ao longo do tempo como um saber profissional em termos de um movimento da profissionalização do professor de matemática. Contudo, isso, como foi sinalizado anteriormente, é outro capítulo da constituição de saberes profissionais para a licenciatura em matemática, que ainda precisa ser mais bem investigado. 


\section{Notas}

1. Na Bahia, o curso de matemática teve seu primeiro ano letivo em 1943. Iniciava-se, dessa forma, quebra da prática monopolizada do engenheiro no exercício do magistério superior e secundário em solo baiano. (DIAS, 2002).

2. O então Instituto de Matemática e Física, em meio a uma violenta rejeição dos catedráticos das escolas tradicionais da UFBA, foi resultado de uma forte articulação formada pelo reitor Edgard Rêgo Santos (1946-1961), pelos professores da Faculdade de Filosofia da Bahia - as professoras de matemática Arlete Cerqueira Lima e Martha Maria de Souza Dantas (1925-2011) e o físico-professor Ramiro de Porto Alegre Muniz (1926-2018) - e, ainda, no âmbito nacional, pelos matemáticos-professores Omar Catunda (1906-1986) e Leopoldo Nachbin (1922-1993), na época, vinculados, respectivamente, à Universidade de São Paulo e ao Instituto de Matemática Pura e Aplicada (IMPA). (DIAS, 2008).

3. Segundo Marques (2010, p.147), no Brasil, a instituição da cátedra, ocorrida no período imperial, deu-se como cargo docente individual, sob a tutela do Estado. Esse posto, de cunho vitalício, poderia ser assumido, pelo menos formalmente, somente por concursos públicos acadêmicos, nos quais o candidato deveria mostrar competência comprovada em uma determinada área de conhecimento. A partir disso “[...] o lente, o catedrático como era chamado o docente que ocupava este cargo, considerava-se e era considerado proprietário daquela área de conhecimento, possuidor do mais alto status e posição na universidade”. (GRACIANI, 1984, p. 82 apud MARQUES, 2010, p. 147). Sob essa ótica, conforme Marques “[a] cátedra era considerada legalmente uma repartição administrativa do ensino superior e do nível secundário” (2010, p.147).

4. Essa análise foi desenvolvida no âmbito de nossa pesquisa de estágio de pós-doutoramento, sob a supervisão do Prof. Dr. Wagner Rodrigues Valente. Ainda, integra o projeto “Tecendo o processo histórico de profissionalização docente, no âmbito da matemática, nos seus diferentes níveis de formação na Bahia”, fomentado pelo Conselho Nacional de Desenvolvimento Científico e Tecnológico (CNPq).

5. Chartier considerou que apropriação, em seu conceito de cultura, dizia respeito às diferentes maneiras com que os objetos (materiais e/ou conceituais) são internalizados, objetivando “[...] uma história social das interpretações, remetidas para as suas determinações fundamentais (que são sociais, institucionais, culturais) e inscritas nas práticas específicas que as produzem." (1988, p. 26).

6. As disciplinas consideradas pedagógicas, nesse ano, permaneceram na FF e, a partir de 1969, foram deslocadas para a Faculdade de Educação.

7. Interpretamos que a disciplina Fundamentos de Matemática Elementar, apesar de ter sido categorizada como um dos cursos básicos vinculados ao Departamento de Matemática Pura do IM, foi, conforme expresso no diário de classe de 1968 (UFBA, 1968f), direcionada unicamente para a licenciatura em matemática. Esse contexto talvez tenha sido estabelecido mediante o que preconizava o Parecer n. 292/1962 em relação a reservar, para além das matérias pedagógicas de cunho geral, mais um semestre para o aprofundamento das especialidades específicas de cada licenciatura (BRASIL, 1962).

8. Os cursos de graduação foram constituídos por um ciclo básico e outro profissional (UFBA, 1968a).

9. Esse Conselho foi criado na Lei n. 4024, promulgada em 20 de dezembro de 1961, denominada de Lei de Diretrizes e Bases da Educação Nacional (LDB).

10. Infelizmente, dos anos de 1972 a 1978, só conseguimos ter acesso no IM as ementas que foram digitalizadas da disciplina Calculo I, as quais que se resumem em uma listagem dos conteúdos que deveriam ser ministrados. Nessas ementas, não há nenhum indicativo dos professores que ministraram aulas nessa disciplina no período em questão, bem como uma explicitação de uma abordagem de ensino. No IM, soubemos que os diários de classes desse período, bem como outros artefatos - que poderiam ser 
transformados em fontes históricas dessa investigação - tinham sido descartados durante a última reforma feita nesse Instituto. Até o presente momento, não obtivemos sucesso em realizar entrevistas e/ ou conseguir depoimentos com alguns personagens que participaram diretamente desse contexto. Vale ressaltar, ainda, que boa parte das fontes interrogadas para esse artigo, datadas antes do ano de 1970, foram gentilmente cedidas pelo Prof. Dr. André Luis Mattedi Dias, que tinha xerocopiado para produzir a sua tese de doutoramento, intitulada Engenheiros, mulheres, matemáticos: Interesses e disputas na profissionalização da matemática na Bahia, 1896-1968, defendida no ano de 2002. Do contrário, seria complicado ou quase impossível construir uma historiografia referente a trajetória do curso de matemática do IM da UFBA nesse período, especificamente, em relação ao ensino de cálculo diferencial e integral.

11. O paulista Omar Catunda (1906-1986), nascido na cidade de Santos, formou-se no ano de 1930 em engenharia pela Escola Politécnica de São Paulo. Contudo, sua longa trajetória profissional deu-se na docência, quando aceitou, em 1934, o cargo para ser assistente do matemático-professor italiano Luigi Fantappiè na cadeira de Análise Matemática da Sub-secção das Ciências Matemáticas da FFCL na recém criada USP. A partir de 1939, assumiu essa cadeira interinamente, tornando-se catedrático dela após realização de concurso em 1944. Omar Catunda permaneceu na USP até o ano de 1962, quando se aposentou e transferiu-se, definitivamente, para a Bahia, em 13 janeiro de 1963. Imediatamente, além do exercício docente, assumiu o cargo de chefe do Departamento de Matemática do IMF e, um pouco depois, em setembro desse mesmo ano, também, a direção desse Instituto. Exerceu essa dupla função administrativa até o ano de 1968, quando o Instituto passou a ser dirigido, em um de seus capítulos emblemáticos, pela Profa. Lolita Carneiro de Campos Dantas, engenheira formada na EP em 1953, na época, livre docente de geometria analítica da Escola Politécnica da Bahia, título obtido em 1965. Omar Catunda, tanto na USP como na UFBA exerceu um papel de liderança entre matemáticos e professores de matemática pelo menos até o ano de 1976, quando obteve sua aposentaria compulsória. (DIAS, 2002; LIMA, 2006, 2016, 2018). Nos exercícios de suas atividades docentes, merece destaque a publicação do seu livro Curso de Análise Matemática, que foi uma das primeiras obras de análise matemática moderna publicada no país em língua vernácula. Tal obra, foi durante muito tempo a única ou principal referência para muitos estudantes e professores, sendo ainda hoje considerada por muitos - a exemplo de Ubiratan D’Ambrosio - “[...]um livro bem escrito, moderno e rigoroso" (apud LIMA; DIAS, 2010b, p.458).

12. As demais disciplinas eram: Cálculo Diferencial e Integral II, Complementos de Matemática e Equações Diferenciais Ordinárias. (UFBA, [1968e?]).

13. Essa entrevista foi realizada no dia 09 de setembro de 2005, nas instalações do IM da UFBA, na cidade de Salvador. Ela foi produzida no âmbito de uma pesquisa de mestrado, intitulada Dos infinitésimos aos limites: a contribuição de Omar Catunda na modernização da análise moderna no Brasil, sob orientação do Prof. Dr. André Luis Mattedi Dias. Atendendo a uma solicitação do Prof. Fernando Sá, essa entrevista não foi gravada. Por esses termos, fizemos as anotações em próprio punho de informações que giraram em torno do percurso profissional de Omar Catunda na UFBA, as repercussões e apropriações de seu curso e livro de análise matemática, bem como sobre a sua influência na vida acadêmica do entrevistado. Posteriormente, essas anotações passaram por um processo de revisão feito pelo próprio Prof. Fernando Sá.

14. O matemático-professor Luigi Fantappiè foi catedrático da cadeira de Análise Matemática da FFCL de 1934 a 1939, quando retornou para a Itália em virtude da Segunda Guerra Mundial. (LIMA; DIAS, 2010a).

15. Para mais detalhes, ver: Lima (2012).

16. Omar Catunda, ao longo de sua carreira universitária, fez algumas explanações sobre o que ele entendia por intuição. Em um desses momentos, Gilberto Loibel, que foi seu aluno entre 1953 e 1954, relembrou que, “[...] em uma conferência que assisti [sic] em meu tempo de estudante o prof. Catunda explanou sua visão sobre a intuição matemática. Ele afirmava algo assim: $\mathrm{Na}$ medida em que um matemático amplia seus conhecimentos ele incorpora em seu acervo novos conteúdos, conceitos, resultados que serão intuitivos para ele assim que ele os domina perfeitamente. Assim o que é teoria difícil para um iniciante 
torna-se material intuitivo para quem já avançou mais. Não existe algo intuitivo em si, mas algo intuitivo para uma determinada pessoa." (LOIBEL, 2005). Essas informações, também obtidas para o desenvolvimento de nossa dissertação de mestrado, foram enviadas pelo Prof. Gilberto Loibel por meio de uma carta digitada, assinada e datada de $1^{\circ}$ a 10 de outubro de 2005 . Essa carta foi em reposta à um questionário com 16 perguntas que nós enviamos ao professor objetivando obter mais informações sobre o percurso profissional de Omar Catunda na USP, as apropriações e repercussões do seu curso e livro de análise matemática, bem como sobre a sua influência na vida acadêmica do entrevistado.

17. Dentre essas professoras, destacamos: Arlete Cerqueira Lima, Jolândia Serra Vila, Celina Bittencourt Marques, Maria Helena Lanat Pedreira de Cerqueira, Adarcy Maria Pereira Costa, Violeta Augusto Rogério de Carvalho e a já mencionada Célia Maria Ganem Pitangueira. (UFBA, 1964; 1968b; DIAS, 2002).

18. Essas aulas foram publicadas, originalmente, no idioma alemão em forma de textos. Em 2004, dois desses textos foram sistematizados e publicados na língua inglesa, em dois volumes, pela editora Dover, sob os seguintes títulos: Elementary Mathematics from an Advanced Standoint: arithmetic, algebra, analysis e Elementary Mathematics from an Advanced Standoint: geometry. Para mais informações, ver: SBM (s.d) e Baldin (2011).

19. Como passou a ser popularmente conhecida a organização curricular da licenciatura, após o Decreto n. 3.454 , de 24 de julho de 1941. Por ele, estabeleceu-se que o curso de didática, a partir do ano escolar de 1942, não poderia ser ministrado em paralelo com nenhum outro curso das seções das faculdades de filosofias, excetuando aqueles que já haviam ingressado até o ano de 1941 (BRASIL, 1941).

20. Formado em engenharia pela Escola Politécnica no ano de 1926, Moura Bastos exercia docência também em escolas secundárias de Salvador, atuando, inclusive, no Ginásio da Bahia. Essa experiência pareceu ter sido determinante para que Moura Bastos conduzisse sua prática docente na FF mais inclinada para os saberes que predominavam nas escolas secundárias. Para mais informações ver: Lima (2019).

\section{Referências}

BALDIN, Y. Y. O Projeto Klein de Matemática em Português: uma ponte entre a matemática avançada e a escola. In: CONFERÊNCIA INTERAMERICANA DE EDUCAÇÃO MATEMÁTICA, 13., 2011, Recife. Resumos [...]. Recife: Comitê Interamericano de Educação Matemática, 2011.p. 1-8. Disponível em: https://xiii.ciaem-redumate.org/index.php/xiii_ciaem/xiii_ciaem/paper/viewFile/2872/1175. Acesso em: 22 out.2020.

BARBIER, J. M. Introduction. In: BARBIER, J. M. (org.). Savoirs Théoriques et Savoirs d'Action. Éducation et formation. Paris: Press Universitaires de France. 2014. p.1-17.

BORER, V. L. Os saberes: uma questão crucial para a institucionalização da formação de professores. In: HOFSTETTER, R; VALENTE, W. R. (orgs.). Saberes em (trans)formação: tema central da formação de professores. São Paulo: Livraria da Física, 2017. p. 173-199.

BRASIL. Decreto n. 19.890, de 18 de abril de 1931. Dispõe sobre a organização do ensino secundário. Rio de Janeiro: Câmara dos Deputados, 1931a. Disponível em: https://www2.camara.leg.br/legin/fed/decret/1930-1939/ decreto-19890-18-abril-1931-504631-publicacaooriginal-141245-pe.html. Acesso em: 25 jun. 2014.

BRASIL. Decreto n. 19.851, de 11 de abril de 1931. Dispõe que o ensino superior no Brasil obedecerá, de preferência, ao systema universitario, podendo ainda ser ministrado em institutos isolados, e que a organização 
technica e administrativa das universidades é instituida no presente Decreto, regendo-se os institutos isolados pelos respectivos regulamentos, observados os dispositivos do seguinte Estatuto das Universidades Brasileiras. Rio de Janeiro: Câmara dos Deputados, 1931b. Disponível em: https://www2.camara.leg.br/legin/fed/ decret/1930-1939/decreto-19851-11-abril-1931-505837-publicacaooriginal-1-pe.html. Acesso em: 13 fev. 2019.

BRASIL. Decreto n. 19.852, de 11 de abril de 1931c. Dispõe sobre a organização da Universidade do Rio de Janeiro. Rio de Janeiro: Câmara dos Deputados, 1931c. Disponível em: https://www2.camara.leg.br/legin/fed/ decret/1930-1939/decreto-19852-11-abril-1931-510363-publicacaooriginal-85620-pe.html. Acesso em: 13 fev. 2019.

BRASIL. Decreto n. 24.279, de 22 de maio de 1934. Aprova a regulamentação do art. $3^{\circ}$ do Decreto n. 19.851, de 11 de abril de 1931, na parte relativa às universidades estaduais e livres equiparadas. Rio de Janeiro: Câmara dos Deputados, 1934. Disponível em: https://www2.camara.leg.br/legin/fed/decret/1930-1939/decreto-2427922-maio-1934-507776-publicacaooriginal-1-pe.html. Acesso em: 13 fev. 2019.

BRASIL. Decreto-Lei n. 1.190, de 4 de abril de 1939. Dá organização à Faculdade Nacional de Filosofia. Rio de Janeiro: Câmara dos Deputados, 1939. Disponível em: http://www2.camara.leg.br/legin/fed/declei/1930-1939/ decreto-lei-1190-4-abril-1939-349241-publicacaooriginal-1-pe.html. Acesso em: 20 nov. 2018.

BRASIL. Decreto-Lei n. 3.454, de 24 de julho de 1941. Dispõe sobre a realização simultânea de cursos nas faculdades de filosofia, ciências e letras. Rio de Janeiro: Câmara dos Deputados, 1941. Disponível em: https:// www2.camara.leg.br/legin/fed/declei/1940-1949/decreto-lei-3454-24-julho-1941-413403-publicacaooriginal1-pe.html. Acesso em: 13 fev. 2019.

BRASIL. Conselho Federal de Educação. Parecer n. 292, aprovado em 14 de novembro de 1962. Dispõe sobre matérias pedagógicas para a licenciatura. Documenta. Brasília, DF, n. 10, p. 95-101, dez. 1962.

BRASIL. Decreto-Lei n. 53, de 18 de novembro de 1966. Fixa princípios e normas de organização para as universidades federais e dá outras providencias. Brasília, DF: Câmara dos Deputados, 1966. Disponível em: https://www2.camara.leg.br/legin/fed/declei/1960-1969/decreto-lei-53-18-novembro-1966-373396publicacaooriginal-1-pe.html. Acesso em: 05 out. 2019.

BRASIL. Decreto-Lei n. 62.241, de 8 de fevereiro de 1968. Reestrutura a Universidade Federal da Bahia e dá outras providências. Brasília, DF: Câmara dos Deputados, 1968a. Disponível em: https://www2.camara.leg.br/ legin/fed/decret/1960-1969/decreto-62241-8-fevereiro-1968-403521-publicacaooriginal-1-pe.html. Acesso em: 24 fev. 2019.

BRASIL. Decreto-Lei Decreto n. 5.540, de 28 de novembro de 1968. Fixa normas de organização e funcionamento do ensino superior e sua articulação com a escola média, e dá outras providências. Brasília, DF: Câmara dos Deputados, 1968b.Disponível em: https://www2.camara.leg.br/legin/fed/lei/1960-1969/lei5540-28-novembro-1968-359201-publicacaooriginal-1-pl.html. Acesso em: 23 fev. 2019.

BRASIL. Indicação n. 8, de 4 de junho de 1968. Dispõe normas para reexame de currículos mínimos e duração de cursos superiores. Documenta. Brasília, n. 87, p. 113-115, jun. 1968c.

CASTRO, A. D. A licenciatura no Brasil. Revista de História, São Paulo, v. 50, n. 100, p. 627-652, out./dez, 1974. Disponível em: http://revhistoria.usp.br/images/stories/revistas/100v2/a09v100n2. pdf. Acesso em: 20 fev. 2019.

CASTRUCCI, B. Entrevista concedida a Sônia Maria de Freitas. In: FREITAS, S. M. Reminiscências. 
Contribuição à memória da FFCL/USP: 1934-1954. 1992. Dissertação (Mestrado em História Social)

- Faculdade de Filosofia, Letras e Ciências Humanas, Universidade de São Paulo, São Paulo, 1992.

CATUNDA, O. Sobre a juventude universitária. A Tarde, Salvador, 12 maio 1973.

CHARTIER, R. A história cultural: entre práticas e representações. Trad. Maria Manuela Galhardo. Lisboa: Difel, 1988.

COMITÊ EDITORIAL. Projeto Klein de Matemática em Língua Portuguesa. Revista do Professor de Matemática, Rio de Janeiro, n. 93, p. 26, 2017. Disponível em: http://www.rpm.org.br/rpm/img/ conteudo/files/Projeto\%20Klein.pdf. Acesso em: 22 out. 2020.

DIAS, A. L. M. Engenheiros, mulheres, matemáticos: Interesses e disputas na profissionalização da matemática na Bahia, 1896-1968. 2002. Tese (Doutorado em História Social) - Faculdade de Filosofia, Letras e Ciências Humanas, Universidade de São Paulo, São Paulo, 2002.

DIAS, A. L. M. O Instituto de Matemática e Física da Universidade da Bahia: atividades matemáticas (1960-1968). História, Ciências, Saúde - Manguinhos, Rio de Janeiro, v. 15, n. 4, p. 1049-1075. out./ dez. 2008. https://doi.org/10.1590/S0104-59702008000400010

FF [FACULDADE DE FILOSOFIA DA BAHIA]. Ata da Solenidade da Fundação da Sociedade Civil da Faculdade de Filosofia da Bahia. Salvador: Faculdade de Filosofia, 13 jun. 1941.

FF [FACULDADE DE FILOSOFIA DA BAHIA]. Regimento interno. Bahia: Imprensa Vitória, 1942.

FFCL [FACULDADE DE FILOSOFIA, CIÊNCIAS E LETRAS]. Anuário da Faculdade de Filosofia, Ciências e Letras (1934-1935). São Paulo: Universidade de São Paulo, 1937.

FFCL [FACULDADE DE FILOSOFIA, CIÊNCIAS E LETRAS]. Programas Aprovados pela Congregação da Faculdade de Filosofia, Ciências e Letras. São Paulo: Universidade de São Paulo, 1953.

GARNICA, A. V. M. Cartografias contemporâneas: mapa e mapeamento como metáforas para a pesquisa sobre a formação de professores de Matemática. Alexandria: Revista de Educação em Ciência e Tecnologia, Florianópolis, v. 6, n. 1, p. 35-60, abr. 2013. Disponível em: https://periodicos.ufsc.br/ index.php/alexandria/article/view/37927. Acesso em: 15 jul. 2018.

HOFSTETTER, R.; SCHNEUWLY, B. Saberes: um tema central para as profissões do ensino e da formação. HOFSTETTER, R.; VALENTE, W. R. (orgs.). Saberes em (trans)formação: tema central da formação de professores. São Paulo: Livraria da Física, 2017. p. 113-172.

LANDO, J. C. Práticas, inovações, experimentações e competências pedagógicas das professoras de matemática no Colégio de Aplicação da Universidade da Bahia (1949-1976). 2012. Tese (Doutorado em Ensino, Filosofia e História das Ciências) - Instituto de Física, Universidade Federal da Bahia/ Universidade Estadual de Feira de Santana, Salvador, 2012.

LARSON, M. S. The rise of professionalism: monopolies of competence and sheltered markets. ed. rev. New Brunswick: Transaction Publishers, 2013.

LIMA, E. B. Dos infinitésimos aos limites: a contribuição de Omar Catunda na modernização da 
análise moderna no Brasil. 2006. Dissertação (Mestrado em Ensino, Filosofia e História das Ciências) - Instituto de Física, Universidade Federal da Bahia/Universidade Estadual de Feira de Santana, Salvador, 2006.

LIMA, E. B. Omar Catunda: venturas e desventuras de um passador cultural. Revista Diálogo Educacional, Curitiba, v. 16, n. 48, p. 445-465, maio/ago. 2016. https://doi.org/10.7213/dialogo. educ.16.048.DS09

LIMA, E. B. Omar Catunda: alguns discursos publicados em jornais sobre os exames e provas dos alunos da Bahia. In: SEMINÁRIO TEMÁTICO: PROVAS E EXAMES E A ESCRITA DA HISTÓRIA DA EDUCAÇÃO MATEMÁTICA, 16., 2018, Boa Vista, RR. Anais [...].[ S.I.: s.n.], 2018, p. 1-12.

LIMA, E. B. The differential and integral calculus as a professional knowledge in the training of the graduate in Mathematics of the Faculty of Philosophy of Bahia (1942-1968). Revista Acta Scientiae, Canoas, v. 21, n. esp., p. 78-91, 2019. https://doi.org/10.17648/acta.scientiae.v21issEid5226

LIMA, E. B.; DIAS, A. L. M. O Curso de análise matemática de Omar Catunda: uma forma peculiar de apropriação da análise matemática moderna. Revista Brasileira de História da Ciência, Rio de Janeiro, v. 3, n. 2, p. 211-230, jul./dez. 2010a.

LIMA, E. B.; DIAS, A. L. M. A análise Matemática no ensino universitário brasileiro: a contribuição de Omar Catunda. Bolema: Boletim de Educação Matemática, Rio Claro, v. 23, n. 35B, p.453-476, abr. $2010 \mathrm{~b}$

LIMA, E. B.; VALENTE, W. R. Análise matemática na Faculdade de Filosofia da Bahia: um curso superior do ponto de vista elementar, 1943-1968. 2019. In: CONGRESO IBEROAMERICANO DE HISTORIA DE LA EDUCACIÓN MATEMÁTICA, 5., 2019, Bogotá. Memorias do V Congreso Iberoamericano de Historia de la Educación Matemática. Bogotá: Universidad Distrital Francisco José de Caldas, 2019. p. 337-344. Disponível em: https://comunidad.udistrital.edu.co/cihem/ memorias/. Acesso em: 14 jun. 2020.

LIMA, G. L. A disciplina de Cálculo I do Curso de Matemática da Universidade de São Paulo: um estudo de seu desenvolvimento, de 1934 a 1994. 2012. Tese. (Doutorado em Educação Matemática) - Programa de Pós-graduação em Educação Matemática, Pontifícia Universidade Católica de São Paulo, São Paulo, 2012.

LOIBEL, G. F. [Correspondência]. Destinatário: Eliene Barbosa Lima. Conceição do Jacuípe, 5-10 out. 2005. 1 carta pessoal, 3p. Respostas para um questionário sobre Omar Catunda e do seu Curso de Análise Matemática.

MARQUES, M. I. C. UFBA na memória. Salvador: EDUFBA, 2010.

NÓVOA, A. O passado e o presente dos professores. In: NÓVOA, A. (org.). Profissão professor. 2. ed. Porto: Porto Editora, 1999. p. 13-21.

SÁ, F. Entrevista concedida a Eliene Barbosa Lima. Salvador, 9 set. 2005.

SBM [SOCIEDADE BRASILEIRA DE MATEMÁTICA]. Projeto Klein de Matemática em Língua Portuguesa, [S. 1., s. d.]. Disponível em: https://klein.sbm.org.br/. Acesso em: 22 out. 2020.

TARDIF. M. A profissionalização do ensino passados trinta anos: dois passos para a frente, três 
para trás. Educação \& Sociedade, Campinas, v. 34, n. 123, p. 551-571, abr./jun. 2013. https://doi. org/10.1590/S0101-73302013000200013

UFBA [UNIVERSIDADE FEDERAL DA BAHIA]. Instituto de Matemática e Física. Relatório de atividades do Departamento de Matemática. Salvador: Arquivo do IM-UFBA, 1964.

UFBA [UNIVERSIDADE FEDERAL DA BAHIA]. Estatuto. Salvador: Beneditina LTDA, 1968a.

UFBA [UNIVERSIDADE FEDERAL DA BAHIA]. Instituto de Matemática e Física. Relatório de atividades do Departamento de Matemática. Salvador: Arquivo do IM-UFBA, 1968b.

UFBA [UNIVERSIDADE FEDERAL DA BAHIA]. Faculdade de Filosofia da Bahia. Diário de classe. Salvador: Arquivo de Memória do Curso de História- UFBA, 1968c.

UFBA [UNIVERSIDADE FEDERAL DA BAHIA]. Faculdade de Filosofia da Bahia. Quadro de pessoal docente de matemática dos departamentos de matemática do Instituto de Matemática e Física. Salvador: Arquivo do IM-UFBA, 1968d.

UFBA [UNIVERSIDADE FEDERAL DA BAHIA]. Instituto de Matemática. Proposta para a divisão em departamentos. Salvador: Arquivo do IM-UFBA, [1968e?].

UFBA [UNIVERSIDADE FEDERAL DA BAHIA]. Faculdade de Filosofia da Bahia. Diário de classe. Salvador: Arquivo de Memória do Curso de História-UFBA, 1968f.

UFBA [UNIVERSIDADE FEDERAL DA BAHIA]. Ata da Reunião dos Professores que Constituiriam o Instituto de Matemática. Salvador: Universidade Federal da Bahia, 17 ago. 1968g.

UFBA [UNIVERSIDADE FEDERAL DA BAHIA]. Instituto de Matemática. Programa da disciplina cálculo I. Salvador: Arquivo do IM-UFBA, 1972.

UFBA [UNIVERSIDADE FEDERAL DA BAHIA]. Instituto de Matemática. Programa da disciplina cálculo I. Salvador: Arquivo do IM-UFBA, 1973-1978.

UFBA [UNIVERSIDADE FEDERAL DA BAHIA]. Instituto de Matemática. Programa da disciplina cálculo I-A. Salvador: Arquivo do IM-UFBA, 1979-1985.

VALENTE, W. R. Saber objetivado e formação de professores: reflexões pedagógico-epistemológicas. Revista História da Educação, Porto Alegre, v. 23, e77747, p. 1-22, 2019. https://doi.org/10.1590/2236-3459/77747 